\title{
Postoperative management of carpometacarpal joint fracture dislocation of the hand: A case report
}

\author{
Timothy Bell MD, Shrikant J Chinchalkar MThO BSc OT OTR CHT, Kenneth Faber MD MHPE FRCSC
}

\begin{abstract}
T Bell, SJ Chinchalkar, K Faber. Postoperative management of carpometacarpal joint fracture dislocation of the hand: A case report. Can J Plast Surg 2010;18(3):e37-e40.
\end{abstract}

Injury to the carpometacarpal joints is rare. The strong ligamentous attachments and carpal bone alignment readily resist displacement. To the authors' knowledge, there are no studies evaluating postoperative recovery regimens of carpometacarpal fracture dislocations. The present study describes a postoperative hand therapy regimen that used a novel carpometacarpal brace permitting early mobilization.

Key Words: CMC joint; Fracture dislocation; Rehabilitation; Splinting

Multiple fracture dislocations of the carpometacarpal I (CMC) joints are rare injuries. The strong ligamentous structures and intricate alignment of the carpal bones readily resist dislocation $(1,2)$. There are numerous case reports and small retrospective studies (3-6) evaluating the treatment and outcome of concurrent $\mathrm{CMC}$ fracture dislocations.

Prokuski and Eglseder (7) produced the largest series of multiple CMC fracture dislocations to date. In their retrospective review at a busy trauma centre, they reported 10 cases of concurrent fracture dislocations of the index through small $\mathrm{CMC}$ joints over a six-year period. The majority of these were caused by motor vehicle collisions. Their outcome variables assessed postoperative pain, grip strength, range of motion $(\mathrm{ROM})$ and return to work. Pain responses were available for all 10 patients. Five of the patients were pain free at the time of final follow-up. The remaining patients had mild activityrelated pain, controlled with activity modification. Strength testing was available for five patients. Grip strength testing at six months postoperatively ranged from $50 \%$ to $90 \%$ of the contralateral limb. Testing revealed full ROM in six patients. The remaining four patients had decreased ROM that was not functionally disabling. Three of the 10 individuals required additional surgery; all required late arthrodesis. Finally, five of the patients were able to return to their preinjury occupations. The authors concluded that early open reduction and internal fixation offered adequate functional outcomes. Other studies (8) have noted similar operative outcomes.

Multiple CMC dislocations are uncommon and, to the best of our knowledge, there are no large studies that have examined postoperative rehabilitation for this injury. A recent review by Feehan (9) emphasized the importance of early controlled mobilization for reducing postinjury complications of the hand. Common complications that result because of prolonged immobilization include stiffness of hand joints, tendon adhesions and muscle weakness (10). Dowden (10) emphasized that early controlled motion must be balanced with sufficient

\author{
Prise en charge postopératoire d'une fracture \\ avec dislocation de l'articulation carpo- \\ métacarpienne de la main : Rapport de cas
}

Les blessures à l'articulation carpo-métacarpienne sont rares. La solidité des ligaments et l'alignement du massif carpien confèrent une résistance à la dislocation. À la connaissance de l'auteur, aucune étude n'a porté sur la prise en charge postopératoire des fractures avec dislocation de l'articulation carpo-métacarpienne. La présente étude décrit un traitement postopératoire de la main ayant fait appel à une nouvelle attelle carpo-métacarpienne permettant une mobilisation hâtive.

immobilization at areas of injury (ie, fractures and dislocations) to ensure that adequate healing occurs.

The purpose of the present study is to describe a novel postoperative rehabilitation regimen in a multiple $\mathrm{CMC}$ fracture dislocation patient. In particular, we emphasize the need for early, protected ROM activity and the use of a carpal stabilization splint to achieve adequate hand function.

\section{CASE PRESENTATION}

A 28-year-old left hand-dominant man sustained an isolated multiple CMC fracture dislocation injury following a motor vehicle collision (Figure 1). Satisfactory closed reduction was not attainable (Figure 2), and open reduction and internal fixation with Kirscher wires was performed through a dorsal transverse incision (Figure 3). The wrist and hand were immobilized in the neutral position for two weeks in a short arm splint and for an additional four weeks in a short arm circumferential cast. The Kirscher wires were removed at the outpatient clinic at eight weeks. Radiographs confirmed union of the trapezium and metacarpal fracture.

Hand therapy, consisting of protective splinting and activeassisted ROM, was initiated eight weeks following injury (Figure 4). The ROM of the affected wrist, metacarpalphalangeal (MCP) and interphalangeal (IP) joints were significantly diminished as a consequence of the injury and prolonged immobilization in a rigid cast (Table 1).

Hand therapy was then progressed to the use of a novel circumferential carpal stabilization brace that the patient wore at all times (Figure 5). The carpal brace extended from the metacarpal heads to the radiocarpal joint. This permitted movement of the radiocarpal and metacarpal joints, while firmly supporting the $\mathrm{CMC}$ articulations. Following removal of the cast, the brace was worn at all times. Hand therapy was undertaken in the brace that consisted of gentle passive wrist, MCP and the IP joint ROM and tendon gliding exercises to overcome the limitations at these joints. A finger flexion

Hand and Upper Limb Centre, St Joseph's Health Care, London, Ontario

Correspondence: Mr Shrikant J Chinchalkar, Hand and Upper Limb Centre, St Joseph's Health Care, 268 Grosvenor Street, London,

Ontario N6A 4L6. Telephone 519-646-6001, fax 519-646-6317, e-mail Shrikant.Chinchalkar@sjhc.london.on.ca 


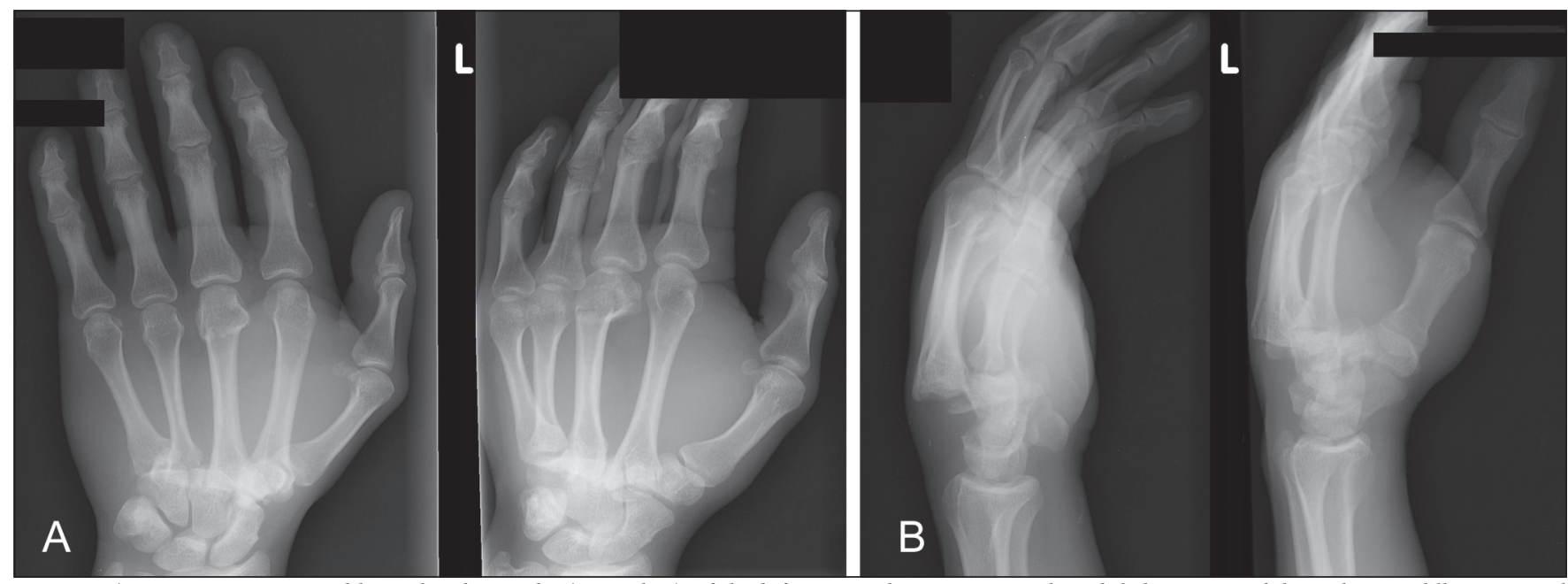

Figure 1) Posteroanterior and lateral radiographs ( $\mathrm{A}$ and $\mathbf{B}$ ) of the left carpus demonstrating dorsal dislocations of the index, middle, ring and small carpometacarpal joint. The fractures of the third metacarpal and trapezium are also visible

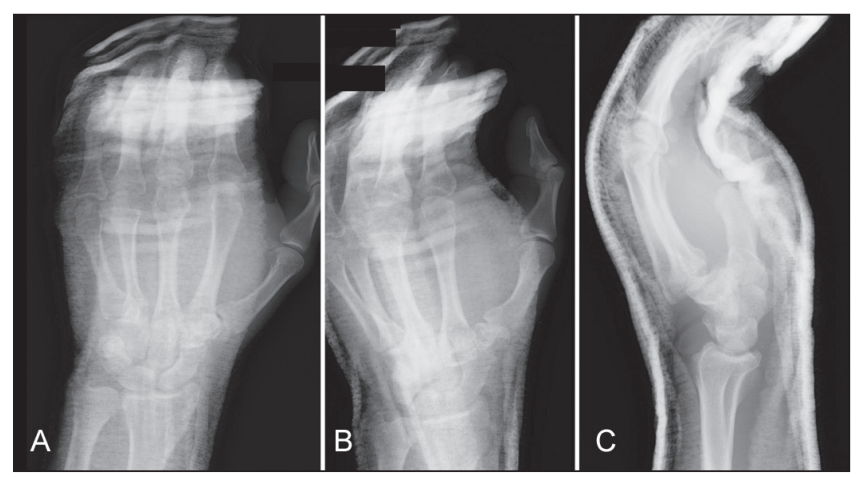

Figure 2) Postreduction films. A Posteroanterior view; B Oblique; C Lateral

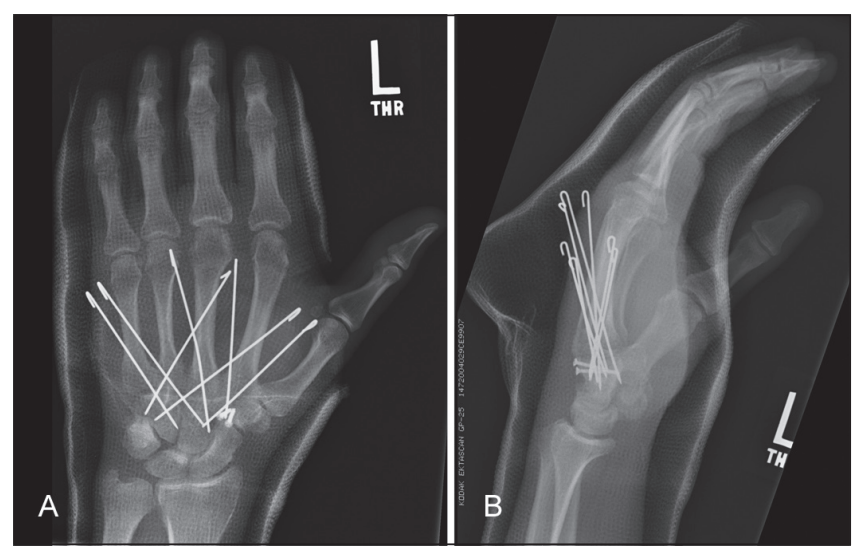

Figure 3) Postoperative films after open reduction and internal fixation. The trapezoid was fixed with two small screws and reduction of the carpometacarpal was maintained with seven directly placed Kirscher wires

glove, which provided passive stretching to the digits, was also used for $5 \mathrm{~min}$ to $10 \mathrm{~min}$ during waking hours. The patient was monitored by the hand therapist on a biweekly basis.

Initially, movements were focused on isolated joints, progressing then to composite movements. Each hand therapy session began with a $10 \mathrm{~min}$ period of hydrotherapy followed by active and passive ROM assessments, ROM exercises, resisted

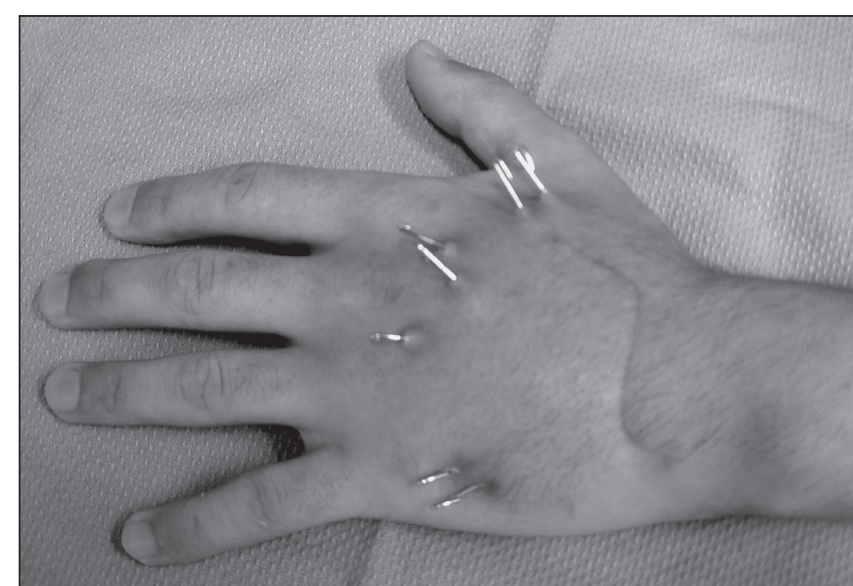

Figure 4) Postoperative week 6. The surgical incision is well healed, and the pin sites appear clean

extensor and flexor gliding exercises with the brace as the patient progressed.

Full ROM was achieved by 10 weeks postinjury (Figure 6). Wrist and grip strengthening exercises were initiated at 12 weeks, at which point the circumferential brace was discontinued.

Grip strength was evaluated using a hand dynamometer.

\section{DISCUSSION}

The CMC joint is a complex joint that readily resists displacement. The bony morphology and the intricate array of ligamentous structures are key in resisting displacement. A recent study by Yoshida et al (2) attempted to model the pathomechanics of ring and small finger $\mathrm{CMC}$ injuries. They concluded that dislocation and injury to this joint occurs through a combination of axial loading and shear stresses around the CMC joint. The majority of concurrent $\mathrm{CMC}$ fracture dislocations are displaced dorsally and result from high-energy trauma such as motor vehicle collisions (7). Because most CMC dislocations are high-energy injuries, they are not usually amenable to closed reduction. Closed management of multiple CMC fracture dislocations frequently results in redislocation (11). Therefore, surgical treatment is the preferred method of treatment (12). 
TABLE 1

Timeline of events and outcome measures

\begin{tabular}{|c|c|c|c|c|c|c|}
\hline Timeline & Week & Event & $\begin{array}{c}\text { Wrist } \\
\text { ROM E/F } \\
\text { (degrees) }\end{array}$ & $\begin{array}{c}\text { MCP } \\
\text { ROM E/F } \\
\text { (degrees) }\end{array}$ & $\begin{array}{c}\text { IP } \\
\text { ROM E/F } \\
\text { (degrees) }\end{array}$ & $\begin{array}{l}\text { Strength } \\
\text { left/right } \\
\quad(\mathrm{kg})\end{array}$ \\
\hline May 15 & 0 & Accident & & & & \\
\hline May 15 & 0 & $\begin{array}{l}\text { Surgical } \\
\text { fixation }\end{array}$ & & & & \\
\hline May 28 & & $\begin{array}{l}\text { Short arm cast } \\
\text { in neutral } \\
\text { position }\end{array}$ & & & & \\
\hline June 31 & 6 & $\begin{array}{l}\text { Removed from } \\
\text { cast; polyfirm } \\
\text { volar splint } \\
\text { created }\end{array}$ & $30 / 40$ & $15 / 25$ & Full ROM & \\
\hline July 5 & 8 & $\begin{array}{l}\text { Pins removed; } \\
\text { flexion glove } \\
\text { and brace } \\
\text { applied }\end{array}$ & $45 / 45$ & $10 / 65$ & & \\
\hline July 26 & 10 & & & Full ROM & Full ROM & \\
\hline August 9 & 12 & Stopped brace & & & & $24 / 55$ \\
\hline Sep 16 & 16 & Strengthening & & & & $35 / 50$ \\
\hline Nov 14 & & Strengthening & Full ROM & Full ROM & Full ROM & $46 / 54$ \\
\hline
\end{tabular}

E/F Extension/flexion; IP Interphalangeal; MCP Metacarpalphalangeal; Nov November; ROM Range of motion; Sep September

Prokuski and Eglseder's (7) report is the largest series of multiple CMC fracture dislocations. They found that surgical treatment within four weeks of injury did not seem to affect functional outcome. Kirscher wires are often used to maintain reduction. They provide stable fixation and can easily be removed after fracture and soft tissue healing. Complications of $\mathrm{K}$-wire use include pin breakage, pin track infection and, rarely, nerve damage (13).

Early mobilization of hand injuries remains a controversial topic. Traditional teaching emphasized immobilization of injuries until bony union was achieved $(11,14)$. Patients would then initiate therapy to regain $\mathrm{ROM}$ after an extended period of immobilization.

Unfortunately, the traditional approach to rehabilitation is fraught with complications. Tendon adhesions and joint

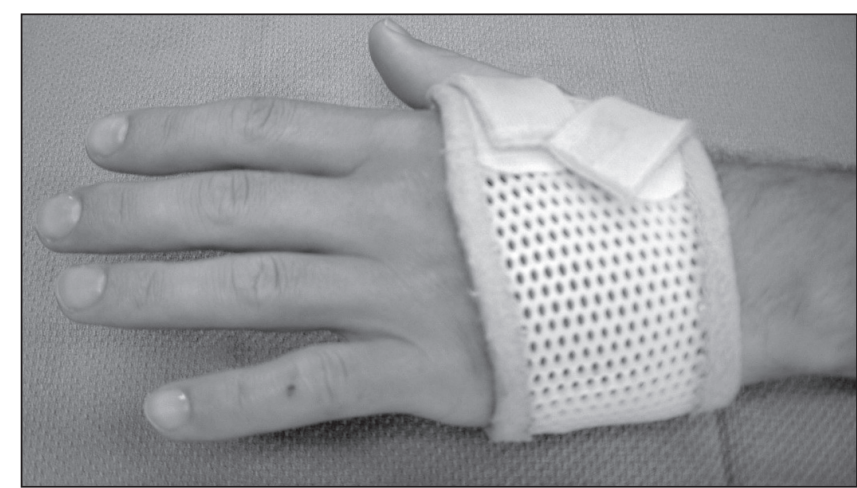

Figure 5) Circumferential carpal brace

stiffness are major problems associated with prolonged immobilization $(11,15)$. Furthermore, surgical intervention is often required to manage such problems. The radiocarpal, MCP and IP are all immobilized in a traditional short arm cast needed to protect the CMC joint. Intrinsic muscle weakness occurs as a result of disuse and $\mathrm{K}$-wire insertion (15).

The authors were able to initiate early controlled mobilization of a concurrent fracture dislocation of the CMC joint through the use of a circumferential carpal brace (Figure 5). This device is similar to other functional splints previously described $(14,16)$. Early in the rehabilitation program, the brace minimizes stress at the $\mathrm{CMC}$ joints, while motion at the radiocarpal, $\mathrm{MCP}$ and IP joints is possible. Later, during the strengthening phase of the rehabilitation, the brace provides circumferential support to the $\mathrm{CMC}$ joints during grip strengthening exercises, minimizing translational and/or rotational forces at the CMC joint during exercises.

Unfortunately, we were not involved in the rehabilitation of the patient at the onset of his injury. As a result, the patient was immobilized in a rigid cast for longer than preferred. Nonetheless, active ROM was started at eight weeks (Table 1). Isolated joint motion and composite motion of the MCP and IP joints were the area of focus, as well as radiocarpal flexion and extension.
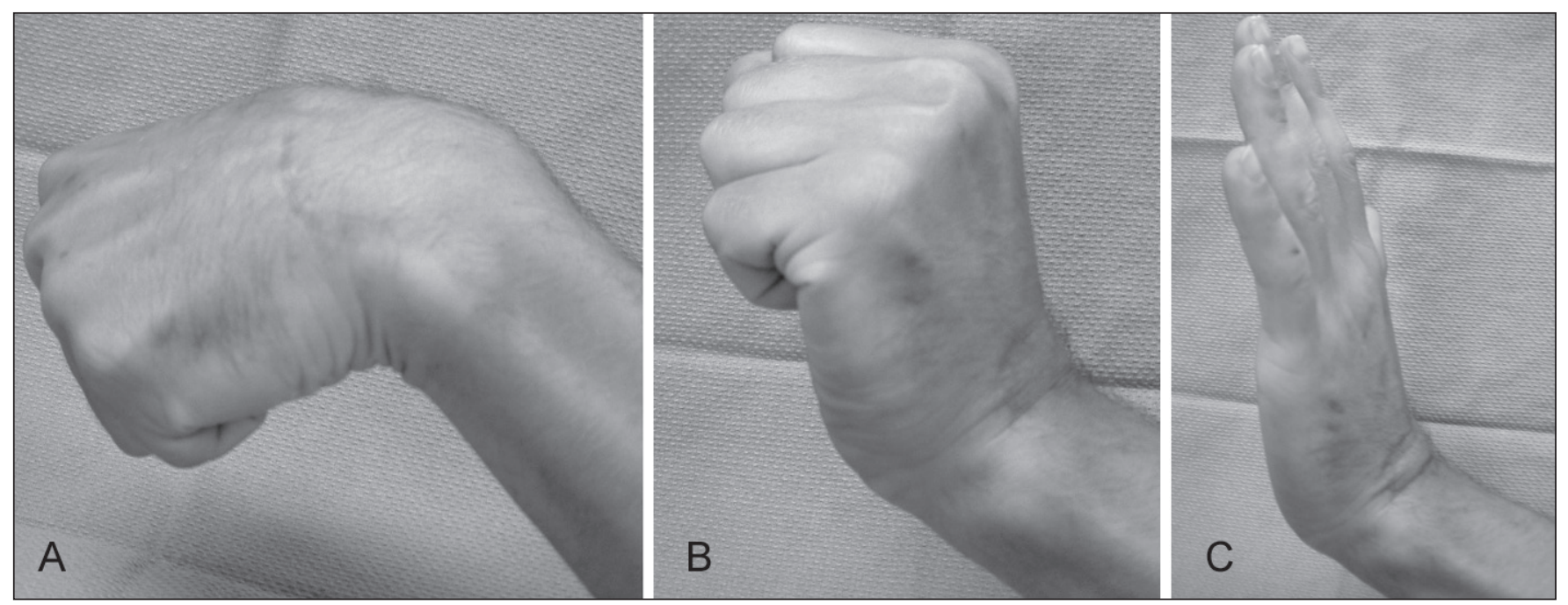

Figure 6) Range of motion at 10 weeks postinjury. $\mathbf{A}$ and $\mathbf{B}$ Wrist flexion and extension with digits flexed; $\mathbf{C}$ Wrist and finger extension 


\section{CONCLUSION}

Multiple CMC fracture dislocations are rare injuries. Complications of prolonged immobilization can be managed by early controlled ROM exercises. The present study describes the use of a novel functional carpal brace that was effective in providing stability to the $\mathrm{CMC}$ joints, while allowing early ROM of surrounding joints. Further studies with larger sample sizes are needed to rigorously test the merit of the brace.

\section{REFERENCES}

1. Nakamura K, Patterson RM, Viegas SF. The ligament and skeletal anatomy of the second through fifth carpometacarpal joints and adjacent structures. J Hand Surg Am 2001;26:1016-29.

2. Yoshida R, Shah MA, Patterson RM, Buford WL Jr, Knighten J, Viegas SF. Anatomy and pathomechanics of ring and small finger carpometacarpal joint injuries. J Hand Surg Am 2003;28:1035-43.

3. Jebson PJ, Engber WD, Lange RH. Dislocation and fracture-dislocation of the carpometacarpal joints. Orthop Rev 1994;Suppl:19-28.

4. Hartwig RH, Louis DS. Multiple carpometacarpal dislocations. A review of four cases. J Bone Joint Surg Am 1979;61:906-8.

5. Liaw Y, Kalnins G, Kirsh G, Meakin I. Combined fourth and fifth metacarpal fracture and fifth carpometacarpal joint dislocation. J Hand Surg Br 1995;20:249-52.
6. Rawles JG Jr. Dislocations and fracture-dislocations at the carpometacarpal joints of the fingers. Hand Clin 1988;4:103-12.

7. Prokuski LJ, Eglseder WA Jr. Concurrent dorsal dislocations and fracture-dislocations of the index, long, ring, and small (second to fifth) carpometacarpal joints. J Orthop Trauma 2001;15:549-54.

8. Schortinghuis J, Klasen HJ. Open reduction and internal fixation of combined fourth and fifth carpometacarpal (fracture) dislocations. J Trauma 1997;42:1052-5.

9. Feehan LM. Early controlled mobilization of potentially unstable extra-articular hand fractures. J Hand Ther 2003;16:161-70.

10. Dowden JW. The principle of early active movement in treating fractures of the upper extremity. 1924. Clin Orthop Relat Res 2006;442:83-6.

11. Amadio PC. Friction of the gliding surface. Implications for tendon surgery and rehabilitation. J Hand Ther 2005;18:112-9.

12. Lawlis JF III, Gunther SF. Carpometacarpal dislocations. Long-term follow-up. J Bone Joint Surg Am 1991;73:52-9.

13. Stahl S, Schwartz O. Complications of K-wire fixation of fractures and dislocations in the hand and wrist. Arch Orthop Trauma Surg 2001;121:527-30.

14. Chinchalkar S, Yong SA. An ulnar boost splint for midcarpal instability. J Hand Ther 2004;17:377-9.

15. Hardy MA. Principles of metacarpal and phalangeal fracture management: A review of rehabilitation concepts. J Orthop Sports Phys Ther 2004;34:781-99.

16. Colditz JC. Low profile dynamic splinting of the injured hand. Am J Occup Ther 1983;37:182-8. 